\title{
The pollutant particle size and chemistry matters
}

3

\author{
Rimantas Kodzius 1,2,3,4, , Dana Khdr Sabir 1,5, Nima Rabiei ${ }^{1}$, Asan Fattah Abdulkareem 1, \\ Xiaohong Wang ${ }^{4}$, Jinfeng Liu ${ }^{4}$, Xiuqing Gong ${ }^{4}$, and Samar Damiati ${ }^{6}$ \\ 1 Mathematics and Natural Sciences Department, The American University of Iraq, Sulaimani (AUIS), 46001 \\ Sulaymaniyah, Iraq; kodzius@envirola.com (R.K.) \\ 2 Ludwig Maximilian University of Munich (LMU), 80539 Munich, Germany \\ 3 Technical University of Munich (TUM), 81675 Munich, Germany \\ 4 Materials Genome Institute, Shanghai University, 200444 Shanghai, China \\ 5 Department of Medical Laboratory Science, Charmo University, 46023 Chamchamal, Sulaimaniyah, Iraq; \\ dana.khdr@auis.edu.krd (D.K.S.) \\ 6 Department of Biochemistry, Faculty of Science, King Abdulaziz University (KAU), 21589 Jeddah, Saudi \\ Arabia; sdamiati@kau.edu.sa (S.D.) \\ * Correspondence: kodzius@envirola.com; Tel.: +370-64455494
}

\begin{abstract}
The air is not the same as thousands and hundreds of years ago. In the air, suspended particles originate from natural phenomena like dust storms or volcanic activities, as well as anthropogenic pollutants such as fuel engine exhaust and everyday activities at home. The total particles in the air can be classified by sizes, such as PM10, PM2.5 or ultrafine particles. However, there are many other important factors in addition to the particle size, influencing the particle behavior and affecting our health. The surface area, chemical and biological composition, aspect ratio, and the charge are all factors characteristic of particles. OoC microfluidic chips are very useful for the pollutant toxicity measurements on various body tissues. A better understanding of pollutants will help to trace these to the potential sources. The data from the on-the-ground and satellite monitoring can be integrated into models, helping to predict and prevent pollution exposure.
\end{abstract}

Keywords: Aerosols, Particulate Matter (PM), PM2.5, nanoparticles, toxicity, source, Organ-on-a-Chip (OoC)

\section{Introduction}

When the living conditions, including the air we breathe, are of good quality, we even do not think about it. The air for the on-the-land living organisms is a medium that we interact all the time. It is like the water for the fishes and other aqua organisms. Mainly lungs and our skin are exposed to the air. The direct contact allows any particles present in the air gasses, to enter the lungs or even the skin. That happens especially if the defense immune system is compromised.

Everyone would like to live in as healthy as possible environment. However, the Earth atmosphere is associated with the natural particle producing phenomena like volcanic activities or forest fires. Humans are additionally exposed to the anthropogenic particle source, such as home-cooking. The recent petroleum oil discovery and industrial revolution brought a range of new and some untested particle pollutants originating from combustion vehicles, plastics or even microand nanosized bead plastic additives [1]. This is a contemporary situation as the pollutants change over time. The pollution sources should be minimized, contained and if possible, completely stopped. 


\section{Aerosols}

The air pollution has adverse effects on people daily lives and the health. Especially the chemical substances and small particles in the air are dangerous through chronic exposure to the body. All the small and microscopic solids or liquids, which are suspended in the air, constitutes the air aerosols. The origins of the aerosols are usually from the land or the sea, when the wind pickups the soil or the salty water particles and suspends into the air, further carrying over the hundreds or thousands of kilometers. The examples of the aerosol origin can be the salt spray containing lots of components present in the seawater (such as sodium chloride $(\mathrm{NaCl})$, magnesium $\left(\mathrm{Mg}^{2+}\right)$, calcium $\left(\mathrm{Ca}^{2+}\right)$, potassium $\left(\mathrm{K}^{-}\right)$or sulfate $\left(\mathrm{SO}_{4}{ }^{2-}\right)$ ions), or dust storms, formed by winds picking up the sand and soil particles, mainly mineral particles from the Earth's crust. While the forming salt sprays are most common over the oceans, the dust storms are a naturally occurring form of pollution in some of the Middle East, African and Asian countries.

The aerosols are formed either both by natural and the anthropogenic (it is also called a human-made) pollution. The main source of the anthropogenic pollution originates from the burning of the fossil fuels, which includes the entire fossil fuel industry. The incomplete combustion, either by coal plants, biomass (wood or other waste), or the exhaust from motor engines produce all kinds of pollutants. We cannot expect the final combustion products to be just water $\left(\mathrm{H}_{2} \mathrm{O}\right)$ and carbon dioxide $\left(\mathrm{CO}_{2}\right)$. The petroleum and oil itself contain various byproducts and Sulphur-containing complex molecules. By burning these, Sulphur oxides $\left(\mathrm{SO}_{x}\right.$, i.e., $\mathrm{SO}_{2}$ ) are released. Sulfur oxide may be further oxidized in the air (for example in the presence of catalyst nitrogen dioxide $\left.\mathrm{NO}_{2}\right)$, forming the dangerous sulphuric acid $\left(\mathrm{H}_{2} \mathrm{SO}_{4}\right)$.

Incomplete combustion of organic matter promotes the release of carbon monoxide (CO). It is clear that acute $\mathrm{CO}$ poisoning is most dangerous, as $\mathrm{CO}$ enters the lung, and binds preferentially to hemoglobin, myoglobin and mitochondrial cytochrome oxidase, thus restricting the oxygen supply $[2,3]$. The $\mathrm{CO}$ gas can also cause the brain lipid peroxidation (degradation of unsaturated fatty acids), leading to the necrosis of the white matter $[4,5]$. The chronic poisoning of $\mathrm{CO}$ is also very dangerous. Even long-term exposure to the low levels of $\mathrm{CO}$ may cause the persistent cerebral (brain) related issues (such as memory loss, depression, headaches) [6], and may worsen cardiovascular symptoms [7]. Usually, removal of the CO source, the symptoms resolve, unless there is an acute $\mathrm{CO}$ poisoning.

The haze, smoke dust, particulate air pollutants, fume, mist, and fog all constitute the aerosols, mainly with the diameter size of $<1 \mu \mathrm{m}$. The suspended particles in the air stay afloat depending on the particle size and other conditions such as temperature and humidity. Usually, the smaller the particles, the longer they stay afloat. The particles of size $<10 \mu \mathrm{m}$ may stay in the air for several weeks [8]. Nano-sized particles are also produced indoors, during some industrial processes (i.e., $\mathrm{TiO}_{2}$ nanoparticle production) or mechanical processes (drilling, abrading, sanding, shredding, etc.). The industrial workers should be conscious of the danger and protect themselves from the released nanosized particles.

We should not underestimate the aerosols in the air, as these may seem harmless, because they may absorb other pollutants. One of these natural sources is volcanic eruptions $[9,10]$, which releases lots of hydrogen sulfide $\left(\mathrm{H}_{2} \mathrm{~S}\right)$ and acids such as hydrochloric acid $(\mathrm{HCl})$ and sulphuric acid $\left(\mathrm{H}_{2} \mathrm{SO}_{4}\right)$ into the air. The volcanic gasses represent aerosols contributing to further chemical reactions in the atmosphere which return to the Earth as acid rains.

\section{The size of the Particulate Matter (PM)}

All the microscopic solid or liquid matter suspended in the atmosphere can be called as Particulate Matter (PM). The size of PM matters (Figure 1). The gaseous contaminants are of a size smaller than viruses $(0.1-10 \mathrm{~nm})$. The soot, tobacco smoke, and smog are of the size of small viruses or the suspended atmospheric dust $(0.01-1 \mu \mathrm{m})$. The oil smoke, fly ash and cement dust are of the size of some allergens (such as dust mites), the bacteria, the mold spores and pollen $(1-100 \mu \mathrm{m})$. 


\subsection{The total particles in the air}

The pollutants in the air can also be grouped based on the particle size influence on human health (Table 1). A high-volume air sampler (sampling more than $1500 \mathrm{~m}^{3}$ of air over a 24-hour period) is capable of measuring the total suspended particulate matter (TSP) which represents the total number of particles suspended in the atmosphere. The biggest particles can be denoted as Suspended Particulate Matter (SPM). The definition and particle size depends largely on the instrumentation used for the collection and estimation of the particle size. For example, dust monitoring equipment from the DustWatch company measures SPM by a cut off at $100 \mu \mathrm{m}$. Then the maximum particle size collected is as close to $100 \mu \mathrm{m}$ as possible [11]. A subclass of SPM smaller particles is defined as Respirable Suspended Particulate Matter (RSPM) or simply Respirable Suspended Particulates (RSP). RSPM is considered more dangerous to health, and the ratio of RSPM to SPM is more important value than SPM alone and may be specific to an area. RSPM is also named as P10 or PM10, although RSPM includes PM10, PM2.5, and other fine particles.

\subsection{PM10}

PM10 are mainly produced by industrial sources, combustion processes, and vehicles.

It is easy to define PM10 as the particles less than or equal to $10 \mu \mathrm{m}$ in diameter. However, this definition is not precise, as the equipment measures the median diameter of the particles. In this way, the PM10 represents the concentration of the median particle size of $10 \mu \mathrm{m}$. Understandably, $50 \%$ of the particles will have a diameter less than $10 \mu \mathrm{m}$, and $50 \%$ of the particles will have diameters larger than $10 \mu \mathrm{m}$.

There are many ways to measure the PM10 number. For example, filter-based gravimetric samplers have the sampling inlet that is directly connected to a filter substrate. Following completion of the sampling period, the PM10 mass collected on the filter is weighted. This procedure, especially the filter changing can be automated. Another method for measuring PM10 in the air is using the so-called Tapered element oscillating microbalance analyzer (TEOM). TEOM is capable of continuously measuring the concentrations of air particles (for example, providing the measurement result every one hour). TEOM has a replaceable Teflon-coated glass filter cartridge (which does not need to be changed as often as in high-volume air gravimetric samplers), and the estimated precision is $+/-0.5 \mu \mathrm{g} / \mathrm{m}^{3}$. The working principle of TEOM is a microbalance, measuring the accumulated weight of the cut-off particles (for example PM10) on a filter cartridge. The accumulated particle weight on the filter is calculated based on the linear dependence of the change of the natural frequency of oscillation and the weight. With the flow rate known, it is possible to calculate also the particle concentration in a given sample.

Besides the filter-based gravimetric samplers (TEOM) there are other methods used in practice for PM measurements such as $\beta$-attenuation analyzers, optical analyzers, the black smoke method and personal samplers [12]. Currently, the gravimetric samplers and TEOM are the most popular methods in the practical applications.

\subsection{PM2.5}

While PM10 particles are generated by both combustion and non-combustion processes (such as industrial processes, motor vehicle engines, the sea salt, windblown dust, and fires), the PM2.5 particles are generated mainly by combustion processes (such as fires, industrial boilers, solid fuel heaters, and motor vehicle engines). The research indicated that the smaller particles, especially the PM less than $2.5 \mu \mathrm{m}$ in diameter are more closely associated with adverse health effects than using measurements of PM10 particles [13]. PM2.5 particles, as well as PM10, are invisible to the naked eye. Simply compare the particle of the size of 2.5 or $10 \mu \mathrm{m}$ with the hair about $60 \mu \mathrm{m}$ in diameter. Understandably, some definitions of PM2.5 as particles only smaller than $2.5 \mu \mathrm{m}$ are oversimplified. According to the International Standards Organization (ISO) [14], the PM2.5 value represents the "particles which pass through a size-selective inlet with a $50 \%$ efficiency cut-off at $2.5 \mu \mathrm{m}$ 
aerodynamic diameter" [15]. The PM2.5 fraction is a standard size fraction where the particle median diameter is $2.5 \mu \mathrm{m}$. Understandably, the PM2.5 contains both the bigger and smaller particles of the size of $2.5 \mu \mathrm{m}$.

The PM2.5 fraction of PM differs from the PM10 just in the size of the particles included, and some same instrumentation can be used to measure PM2.5, by applying different filters. In practice, the measurement of PM2.5 is more complicated, as the total mass of PM2.5 particles is lower compared to the bigger particles. Therefore, the coarse fraction should be excluded, and more accurate methods are required. The methods for the smaller size PM2.5 fraction follow the same principles as those for PM10 measurement. The reference methods for PM2.5 are not capable of producing real-time data. Therefore, equivalent methods are used. Commercial companies sell instruments suitable for PM2.5 measurements. A group of non-reference manual gravimetric samplers is called Partisols (i.e., such as Partisol 2025 instrument) [16,17]. The gravimetric samplers employ a sequential sampling system of filters that enables up to several fixed 24-hour period particulate samples, requiring visits every two weeks to exchange filter cassette magazines.

The automatic instruments Filter Dynamic Measurement System (FDMS) (made by Thermo) [18] and Beta Attenuation Monitor (BAM) (made by Met-One) [19,20] deliver automatic data. The FDMS is based on TEOM. On FDMS, both volatile and non-volatile measurements are made.

In practice, measurement of the mass is complicated by the presence of some other (semi-volatile) particles, humidity, and other factors. Therefore, the PM2.5 metric does not correspond to definite physical components of the air but is in effect defined by the measurement method.

\subsection{Ultrafine Particles}

The most health-damaging particles are in nanometer size that are capable of passing through the cell membrane, migrating to other organs such as the brain, reaching and damaging the cardiovascular system [21]. The ultrafine particles (UFP) are commonly defined as particles in the size of $<100 \mathrm{~nm}(<0.1 \mu \mathrm{m})$ in diameter. UFP is also labeled as PM0.1.

Understandably, the measurements are based not on the mass (as UFP contribute very little to the mass), but on trying to quantify the particle number in the air. Instead of conventional light scattering methods (which cannot detect the ultrafine particles), the Condensation Particle Counter (CPC) is used [22,23]. The sampled air passes through a compartment that is saturated with alcohol vapor, which will condense on the small particles. The particles will grow in size and are counted in an optical detector. The CPC is capable of measuring the particles within the range of $3-2000 \mathrm{~nm}$. Another method for ultrafine particle detection and counting is the Scanning Mobility Particle Sizer (SMPS) [24,25], where particles are separated according to the electrical mobility. The particle concentration can be measured for the particles within the range $11-450 \mathrm{~nm}$.

As we mentioned previously, the smaller and lighter particles (such as in size of $<10 \mu \mathrm{m}$ ) tend to stay in the air longer, and the particles in the size of $<1 \mathrm{~nm}$, stay even for weeks. For example, the small particles such as Diesel particulate matter (DPM) are in size of $<100 \mathrm{~nm}$, are emitted from diesel engines, and have the highest concentration near the source of emission (such as highways or cities). The small particles are usually removed by precipitation (such as rain).

\section{The factors influencing the particle effects}

While it is a well-established the fact that the particle size has an enormous impact on cell and tissue (and therefore, our body) health, other factors are as important. The particle surface area is related to the particle size. Nanoparticles follow collective behavior that could be described by quantum physics. Particle chemistry (identifying what the particle is made of) is also important for its reactivity and interaction with other chemicals and the cells. Biologicals such as DNA and proteins on the particles have an impact on our cells, especially affecting the immune system. 


\subsection{Particle surface area}

Multiple studies support the view that the health hazard is related to the particle size, that is the smaller particles, the deeper they are capable of penetrating into our lungs, and the cardiovascular system, then accumulates and damage our organs. The measurement methods, however, usually measure the total mass of particular fraction (PM10, PM2.5). From this measurement, the particle count (a numerical quantity) can be derived. Some legislative limits for the diesel engine emissions are based on mass. However, the total mass of specific fraction of the particles is not a proper measure of the health hazard. For example, one $10 \mu \mathrm{m}$ diameter particle has the same mass as 1 million particles of $100 \mathrm{~nm}$ diameter. Understandably, one larger particle is less hazardous than million smaller particles which are more capable of entering the alveoli.

We provide a simple explanation in mathematical terms, how the cube can be divided into eight smaller cubes, with following the increase of surface area (Figure 2). The volume, however, remains constant. We suppose a cube $B=\{(x, y, z) \mid 0 \leq x \leq l, 0 \leq y \leq l, 0 \leq z \leq l\}=[0, l] \times[0, l] \times[0, l]$ is given. Then the surface area of the cube is $s=6 l^{2}$. If the cube is divided into sub-boxes, then the surface area increases. We do this by dividing each of the intervals $[0, l]$ into $n$ sub intervals $\left[l_{i-1}, l_{i}\right]$ of equal width $\Delta l=\frac{l}{n}$. The planes through the endpoints of these sub-intervals parallel to the coordinate planes divide the box $B$ into $n^{3}$ sub-boxes $B_{i j k}=\left[l_{i-1}, l_{i}\right] \times\left[l_{j-1}, l_{j}\right] \times\left[l_{k-1}, l_{k}\right]$. Each sub-box has surface area $\Delta s=6 \Delta l^{2}=6 \frac{l^{2}}{n^{2}}$. Then we form the sum $T_{s}=\sum_{i=1}^{n} \sum_{j=1}^{n} \sum_{k=1}^{n} \Delta s=n^{3} \Delta s=$ $n 6 l^{2}=n s$, to obtain the total surface area, where s is the surface area of the cube $B$. So, the total surface area after dividing the box into $n^{3}$ sub-boxes is $\mathrm{n}$ times as much as the surface area of the box $\mathrm{B}$, that is $\frac{T_{s}}{s}=n$. For example, in Figure $2, l=2$ and the box is divide into $2^{3}=8$ sub-boxes. The surface area of the box is $24 \mathrm{~m}^{2}$ and the total surface area after cutting increases and becomes $48=2 \times 24 \mathrm{~m}^{2}$. Further division of resulting cubes into next eight cubes will result a total surface area of $96 \mathrm{~m}^{2}$.

An important factor for the health is the particle surface area. Comparing the same mass fractions of different size particles, the smaller particles will have proportionally bigger the surface area, as there are much more particles in smaller diameter size fraction, compared to the bigger diameter particles (Figure 2). The particle interacts with the human cells and cell compartments through its surface, inhibiting the vital enzymatic reactions [26]. There are no straightforward methods to measure the particles surface area. One of the methods utilizes an attachment of heavy labeled atoms (such as ${ }^{211} \mathrm{~Pb}$ ) to the particles. The aerosol particles are captured on a filter, and the signal is measured by an $\alpha$-counter (such as epiphaniometer). The measured signal corresponds to the transferred mass, which is proportional to the particle surface area [27]. Another method to measure the particle surface area is based on measuring the particle number size distributions. With the estimated particle geometry, the distributions can be converted to surface area. Usually, an SMPS is used for measuring smaller particles (with diameters from $2.5 \mathrm{~nm}$ to $1000 \mathrm{~nm}$ ) [24], and the Aerodynamic Particle Sizer (APS) is used for the larger particle size fractions $(0.5$ to $20 \mu \mathrm{m})$ [28,29].

The surface area plays a huge role when the biological molecules or chemicals interact with the surface (Figure 2). As an example, the large surface may adsorb some proteins (such as polymerases) or other molecules, which become inactivated and not available anymore for the reactions [26]. In this publication, we demonstrated the potential inhibition of the biological molecule (such as an enzyme) on the microfluidic material surface. For the small pollutant particles, it is opposite. The large pollutant surface may act inhibitory on the lung cells.

The data for particle number, size, surface area, and morphology are very important. It is confirmed and well acknowledged that the respirable (PM10) and fine suspended particles (PM2.5) are more dangerous to health than larger particulate up to $100 \mu \mathrm{m}$. There is clear evidence that both PM2.5 and PM10 cause additional hospital admissions and premature deaths of the old and sick on high pollution days. PM has a significant contributory role in human all-cause mortality and in particular in cardiopulmonary mortality. Even the short-term particle exposure (such as during dust storms or other pollution episodes) worsens the asthma symptoms and even worsening 
the general condition leading to lower level of activity. A recent review by Schulze et al. describes the impact of various pollutant particles on human health [30].

Even modern diesel engines emit lots of particles (such as DPM) in size range of $100 \mathrm{~nm}(0.1$ $\mu \mathrm{m})$. These soot particles can carry carcinogens like benzopyrenes which are adsorbed on the particle surface. Currently, the car manufacturers are trying to minimize the problem with various particulate filters. That does not work well in a weak regulatory environment, such as in developing countries where the filters in the cars are not present.

\subsection{Chemical particles composition}

Knowing the particles chemical composition helps to identify the source and allows estimating the particle distribution. There have been attempts to determine the particle composition. In an experiment in 2008, PM2.5 particles were collected. The further analysis of the composition indicated the three components that account for a large proportion of the total mass: organic carbon (organics), nitrate $\left(\mathrm{NO}_{3}^{-}\right)$, and sulfate $\left(\mathrm{SO}_{4}^{2-}\right)$ [31].

Primary (from road traffic), as well as domestic (oil and solid fuel) combustion contributes to the elemental carbon (C), as well as the organics. Studies showed a clear link between the traffic emissions and its significant contribution to black carbon concentrations. We denote the black carbon as the sooty black material emitted from car engines and other sources that burn fossil fuel. Hourly measurement over the day indicated that the black carbon concentrations are most significant during the evenings, which is produced by the use of solid or liquid fuel for domestic heating [32].

The emissions from the road traffic, such as road abrasion or tire and brake wear are non-exhaust emissions of PM2.5. Understandably, emissions increase with increasing traffic levels. Non-exhaust traffic emissions also produce iron-rich (Fe) dust. It is important to measure iron in the particles, as it allows to understand the pollution source since iron is a marker for non-exhaust vehicle emissions. While the electric-powered cars considered as "clean cars", they mainly would contribute to the road and tire abrasion, as well as the brake wear pollution sources. The construction industry (including construction and demolition, mineral and cement handling), as well as wind-blown soil, produce particles rich in calcium $\left(\mathrm{Ca}^{2+}\right)$ salts. Sodium chloride $(\mathrm{NaCl})$ in the dust usually comes from the sea salt.

An increase in nitrate $\left(\mathrm{NO}_{3}^{-}\right)$was observed in some instances of high PM2.5 pollution [33,34]. The authors state that it is important to understand the origins of higher nitrate concentrations in PM2.5 particles and suggest measuring the air quality and the particle chemistry both on the roads and in the rural areas. It is recommended to have the following smallest set of accessed chemical species in the measurements: elemental carbon (EC), organic carbon (OC), sodium $\left(\mathrm{Na}^{+}\right)$, potassium $\left(\mathrm{K}^{+}\right)$, calcium $\left(\mathrm{Ca}^{2+}\right)$, magnesium $\left(\mathrm{Mg}^{2+}\right)$, chloride $(\mathrm{Cl}-)$, ammonium $\left(\mathrm{NH}^{4+}\right)$, nitrate $\left(\mathrm{NO}^{3-}\right)$, sulfate $\left(\mathrm{SO}_{4}{ }^{2-}\right)$, and iron $(\mathrm{Fe})$. Interestingly, the chemical correspondence of nitrate and sulfate with ammonium indicated the neutrality of the particles and the complete chemical formula is ammonium nitrate $\left(\mathrm{NH}_{4} \mathrm{NO}_{3}\right)$ and ammonium sulfate $\left(\left(\mathrm{NH}_{4}\right)_{2} \mathrm{SO}_{4}\right)$. One can imagine the complex interaction of ammonium ( $\mathrm{NH}_{3}$ ) (which is usually in excess) with $\mathrm{NO}_{x}$ and $\mathrm{SO}_{2}$, whereas the ammonium level is controlled by strong acids such as hydrochloric $(\mathrm{HCl})$, nitric $\left(\mathrm{HNO}_{3}\right)$ and sulphuric $\left(\mathrm{H}_{2} \mathrm{SO}_{4}\right)$ acids. A secondary pollutant PM sulfate is stable in the atmosphere and, once formed irreversibly, will not decompose back to ammonia and sulphuric acid vapors under normal atmospheric conditions. However, the secondary PM ammonium nitrate $\left(\mathrm{NH}_{4} \mathrm{NO}_{3}\right)$ is thermally unstable and may revert to nitric acid $\left(\mathrm{HNO}_{3}\right)$ and gaseous ammonia $\left(\mathrm{NH}_{3}\right)$ within minutes to hours depending on atmospheric conditions.

Primary emissions from road traffic also contribute to regional secondary PM through the oxidation of emissions of nitrogen oxides. The primary pollution sources do not contribute to all of the PM found in the atmosphere. The significant amount of secondary PM is formed in the atmosphere by chemical reactions from the primarily emitted precursors. Secondary PM over a large 
area can be formed by emissions of the gaseous pollutants ammonia, oxides of nitrogen and sulfur dioxide from various sources.

The monitoring of particulate lead $(\mathrm{Pb})$ (since around 1985) allowed to understand the dangers of the lead-in petrol and led to the ban on sales of leaded petrol (in 2000) [35]. Despite the ban, around eighteen countries (including Algeria, Yemen, and Iraq) continue using leaded gasoline due to short-sighted economic benefits [36]. The lead exposure includes neurotoxic effects, such as low IQ and antisocial behavior, especially affecting children.

In some countries (for example, UK), the measurement of metals in small particles is based on PM10 fraction. The particles are sampled by taking a known volume of air through a cellulose filter, which is located in a low- or high-volume sampler. The cellulose filter is then dissolved in an acid mixture $\left(\mathrm{HNO}_{3}\right.$ and $\left.\mathrm{H}_{2} \mathrm{O}_{2}\right)$, with following metal analysis by inductively coupled plasma-mass spectrometry (ICP-MS). ICP-MS is a very sensitive technique and is especially suitable for detecting the trace elements. Mainly the concentrations of nickel (Ni), arsenic (As), cadmium (Cd), and lead $(\mathrm{Pb})$ are routinely accessed.

Major ions, especially sulfate anions, are measured similarly. First, the particles are captured on a cellulose acetate filter. Then, after the aqueous extraction, the sample is analyzed by ion chromatography (IC). Some other methods are applied to detect ammonium ions $\left(\mathrm{NH}^{4+}\right)-$ here flow injection permeation/conductivity measurements are performed.

Polycyclic aromatic hydrocarbons (PAHs) are a class of chemicals, which are nonpolar and lipophilic, posing health risks. The exposure to humans leads to cancer, cardiovascular diseases and have an impact on fetal development. PAHs are routinely monitored due to its toxicity. While PHAs are monitored in the PM15, and PM10 particles, more advanced methods allow monitoring PAHs concentration also in smaller particles. The PAHs are captured in the volatile and non-volatile phases and collected using polyurethane (PU) foam plugs or filter papers. PAHs can be extracted using dichloromethane. The following gas chromatography with the mass spectrometric detection (GC-MS) allows quantification of many individual PAHs (even 32 different formulas). The main PAHs routinely measured are acenaphthene, anthracene, benzanthracene, benzfluoranthracene, benzoperylene, benzopyrene, chrysene, fluorene, phenanthrene, and pyrene [37].

\subsection{Other PM factors to consider}

Besides the PM surface area and the surface chemical composition, there are many known and yet to discover important factors to mention.

\subsubsection{Particle collective behavior}

The smaller particles, especially in large numbers, obey the law of particle physics, which are different for the bulk materials. Especially the nanoparticles (smaller than $1 \mu \mathrm{m}$ ) exhibit the collective behavior, and the group of such particles sometimes is denoted as the nanoparticulate matter. The nanomaterials also differ from the bulk materials in surface and quantum effects [38]. The surface area for the small nanoparticles massively increases, with the effect that surface atoms have a different environment to interior atoms. Such size effect is notable for the nanoparticles smaller than $\sim 5-50 \mathrm{~nm}$ [39]. One can calculate that from several hundred to $10^{5}$ atoms are present in one nanoparticle of size 1 or $100 \mathrm{~nm}$. Recent evidence has shown that PM0.1 can aggregate into larger particles about the size of PM2.5 [40].

\subsubsection{Particle shape}

The particles shape is also of high importance. Asbestos consists of long microscopic fibrils ( 0.1 $-10 \mu \mathrm{m}$ ) with 1:20 aspect ratio. The inhalation of asbestos dust allows the small particles with sharp angles to penetrate and damage lungs. Usually, the higher the aspect ratio, the more toxic is the 
asbestos particle [41]. In the case of nanoparticles, these are usually classified to one-, two- or three-dimensional nanomaterials. Asbestos fibers represent 2D-nanoparticles.

\subsubsection{Particle charge}

With the artificial production of various kinds of nanoparticles in the laboratory, we should take into account also the composition (made of a single or from several materials), magnetic and electromagnetic properties. Such properties influence the nanoparticles clustering (agglomeration) when these particle clusters behave as larger particles. Some studies showed the faster diffusion of negatively charged latex nanoparticles across the mucus layer of the gastrointestinal tract, while the positively charged particles were trapped in the negatively charged mucus $[42,43]$.

\subsubsection{A particle as a biological and genetic information carrier}

The dust particles, including the pollen grains from the male seed plants, are the carrier of genetic (DNA) and biological (such as proteins) information. The human immune system may react to the inhaled pollen by allergic reactions. Mainly the proteins of the pollen surface cause the immune reactions, such as allergy or asthma. The human immune system cross-reacts to a wide range of carriers, the allergens. The same protein, having a similar structure but coming from various sources (such as flees, cat fur, etc.) potentially can cause immune reactions [44-46]. There are attempts to classify the allergens and expressed proteins based on their encoding DNA. More allergens have been identified, with more of the research needed to analyze the effect on human body $[47,48]$. Metagenomics methods allow collecting the particles in the air over time, extracting the metagenome DNA, with following sequencing of all DNA. The sequencing enables understanding the species (such as bacteria, fungi or other microbes) which "inhibit" or deposits its DNA or proteins on the dust particles [30,49].

\section{Pollutant toxicity measurement utilizing OoC}

The toxicity test for the health and environmental regulations should account for the nanoparticle size, surface reactivity, and possible agglomeration. There are a lot of human-made products that include nano and microparticles: food additives, toothpaste, cosmetics, sunscreens, stain-resistant clothing, tires, etc. While some of the nanoparticles (such as $\mathrm{TiO}_{2}$ for sunscreen) are standardized and their health effect is known, for other, especially novel particles, extensive toxicity tests should be done until they are allowed to be incorporated into our daily products. Not only the health effects on humans are important, but we should also consider the distribution ways delivering the particles through the tap water to our rivers and oceans, impacting the aqua-living organisms. There is still no simple relationship between the nanoparticle classification (such as dimensionality, morphology, composition or agglomeration state) and health effects. We should mention that not all nanoparticles are toxic - some seem to be non-toxic [50,51], and other find a wide spectrum of applications in the healthcare system [52]. For more detailed studies on health effects of PM and nanoparticles, we recommend recent reviews [53-56].

The development in Organ-on-a-Chip area allows monitoring the growth of mammalian cells over an extended period. By including some chemicals, representing pollution sources, the growth and any abnormalities in cells can be observed. The toxicity (damage to the cells) and the dose can be determined [57]. We envision OoC methodology as the fast, ethically responsible (no animals involved in the research) and available to measure particle toxicity effects for any laboratory equipped with mammalian culture room $[30,58]$. 


\section{Tracing the source of the pollutant}

One of the reasons to detect pollutant and measure their concentrations is to understand what these pollutants are, where do they come from and how to avoid them. Both the chemical (metals, organics, etc.) and biological (species, DNA, proteins, metabolites other molecules) properties can be analyzed, both qualitatively and quantitatively to understand pollution and its source.

Sometimes, even a single chemical or even an elemental tracer can be used as a marker that indicates the origin. For example, sodium $(\mathrm{Na})$ in the pollutant indicates the sea salt as a source, and the presence of aluminum and silicon indicates the soil and crustal dust as an origin. Fuel oil combustion can be detected by the presence of vanadium $(\mathrm{V})$ and nickel $(\mathrm{Ni})$, whereas the vehicle brake wear produces barium (Ba) pollutants. The combination of chemical components allows easier identification and quantification of sources. Of course, various localities have specific pollutant sources, and this should be taken into account.

The biomass burning can be identified by a single marker, the carbohydrate compound levoglucosan [59,60]. Levoglucosan is an organic compound with a six-carbon ring structure formed from the pyrolysis of carbohydrates, such as cellulose. The wood smoke also contains other tracers, such as fine particle potassium (K). However, the potassium produced by the wood smoke should be differentiated from wind-blown soil and sea salt, as well as the road traffic. The wood smoke to fine particle potassium mass ratio depends on wood combustion conditions, and the wood smoke mass is measured by the Aethalometer [61,62]. The quantitative discrimination of carbonaceous particles produced by the wood burning and road traffic emission can be done by utilizing aerosol light absorption measurements [62]. Another, and the most reliable way of estimating wood smoke mass is from the analysis of radiocarbon isotope $\left({ }^{14} \mathrm{C}\right)$. This kind of radiocarbon is associated with present-day sources of carbon and not with fossil sources. Heal et al. analyzed PM2.5 samples for the radiocarbon. By thermal separation of elemental carbon from organic, they were able to determine the radiocarbon content of each. Finally, they disaggregated the carbonaceous components of PM2.5 into EC or OC, originating from biomass (such as burning wood or contemporary fuels), fossils (road vehicle engines or coal combustion), and biogenic carbon (from vegetation waste and other biogenic precursors) [63].

The secondary organic matter can be calculated from the excess of $\mathrm{OC}$ when the ratio between primary OC and EC is known. While there is still a correction needed, because the analysis of radiocarbon overestimates the OC : EC ratio, the method is advantageous as it allows to distinguish between organic material derived from fossil fuel sources and that from biogenic sources [64]. The work on Yin et al. analyzed the sources of the organic compounds in the atmosphere. The analysis of a large number of organic molecular markers within the PM, such as sterols, organic acids, n-alkanes, hopanes, PAHs, also some trace elements [65] allowed to disaggregate the OC into various source components [66]. Following OC sources could be identified: wood smoke, vegetative detritus (i.e., fragments from plants, such as leaves), suspended dust and soil, particles from diesel, gasoline or smoking engines, also the particles from coal or natural gas combustion.

Organic and biological molecules can be utilized for tracking the pollution sources originating from the food production. Even simple cooking of the meat or corn oil produces a cooking aerosol with unique molecules suitable to serve as the tracers. The peptide mass fingerprinting (PMF) with the aerosol mass spectrometer (AMS) can identify and distinguish unique molecules such as cholesterol or peptides, which are not present in other sources like coal burning or road traffic $[66,67]$.

The life forms and the viruses are the carriers of the coding DNA or RNA. Many of potentially harmful microorganisms attach to the dust particles and are carried over long distances. Metagenomics (DNA sequencing of captured species) allows identifying and tracing such pollutants originating from microorganisms [68]. It is anticipated that not only DNA and RNA analysis can be utilized to trace living organisms, but also the proteins, peptides or other molecules unique to specific species (by mass-spectroscopy or other methods). 


\section{Summary}

Looking back to the 18th century, with the cities grow and development of the transportation by horses, the main problem was the horse manure (stool), that was accumulating on the city streets and in the open places. The dust from manure is, of course, potentially very health damaging due to various allergens present in the biologicals. Nowadays transportation is based on fuel-powered engines. However, there is a connection between the health effects (such as cancer rates) and how much car engines omit the PM. Despite the requirements to equip the vehicles with diesel particulate filters, and "clean" car manufacturer tests, the situation on the streets look different. In reality, many cities are starting to ban diesel-powered vehicles to enter the city center. Some cities are planning to ban both gasoline- and diesel-powered vehicles. Fortunately, the development of alternatively powered cars is rapidly advancing. Nowadays it is possible to purchase a hybrid or a fully electric car from the most of the car manufacturers. With the development of necessary infrastructure, we can hope our future will look bright. Some problems, however, will have to be solved. How will the non-exhaust emissions be solved? Such as the PM generation from the road itself, from the vehicle tires and brakes, or dust particles on the road. With all of our desire to live in a clean environment, we can anticipate the technological advancements for the tire materials, as well as for the road material. Currently, the PM2.5 : PM10 mass fraction is measured to estimate the non-exhaust traffic sources.

Besides the traffic-related pollution, there are other, industry-related PM sources. One can expect the energy source based on the coal and diesel to diminish to the minimum or go away at all. The human is responsible for the anthropogenic pollution sources, and with right policies, this can be handled in the right way, leading to the much cleaner environment, for the benefit of the healthier population. The non-anthropogenic pollution sources, such as dust storms, are much more difficult to control, if at all. However, the monitoring stations, located in each of the city, other locations will help to predict, detect and follow the pollutants. With the advanced technology, the pollutants can be followed from the source, moving over territories and continents. Besides the on-ground meteorological stations, the PM can be monitored utilizing satellites. The satellites are progressively involved in detecting and analyzing not only the particle size but also the pollutant cloud size, the chemistry, even secondary reactions in the atmosphere [69,70]. With the ongoing integration of the data sources, both from the meteorological stations and satellites, we can expect more precise information on the pollutant kind and the toxicity to the population. Informed people can adjust behavior, such as how much time to spend in outside activities, and how much and what kind of protection is needed. That happens right now in developing and developed Asian countries such as Singapore, Hong Kong or China. People can read the air quality values on TV, on the internet, and probably by the fastest way - on the mobile phones.

There are different modeling methods for the primary and secondary pollutants, PM concentration, and distribution. The models allow assessing the PM concentration in the locations where monitoring stations are not available and allow to estimate the PM change in the future. Despite the many uncertainties in the data and processes, Pollution Climate Mapping (PMC) [71] and the ADMS-Urban models [72,73] are few of examples worth mentioning.

Ideally, the technologies would help to detect the pollution source as early as possible. With the right policies in place, the pollution can be minimized. To enable the enforcing these policies, an effective and PM detection technology is needed. Overall, the long-term records are necessary to understand the pollution itself, for the delivering suitable policies and actions on the concentration of any given pollutant. 


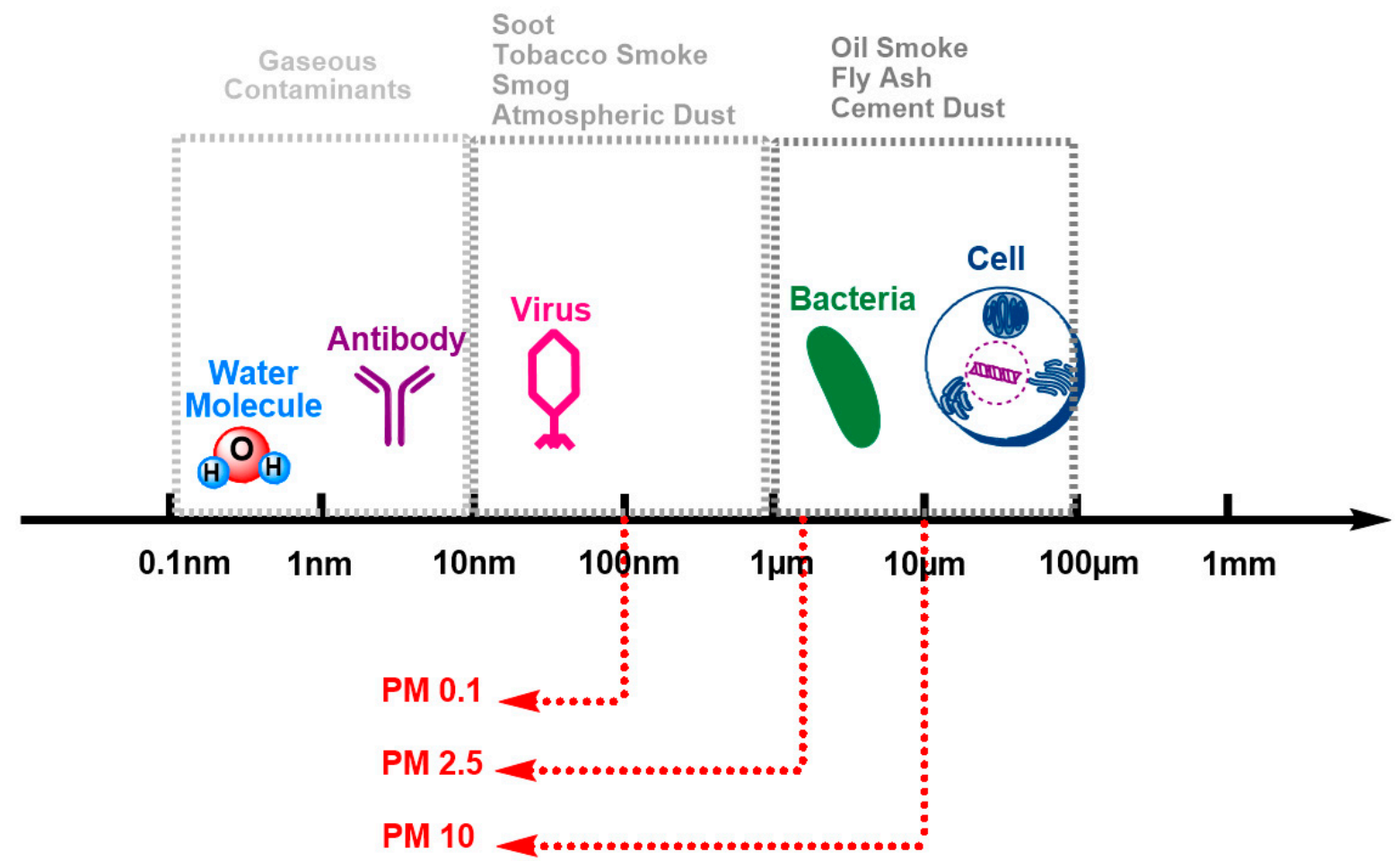

Figure 1. The size comparison of various contaminants (gaseous phase, soot, smoke, dust particles) with the chemical and biological molecules and cells. PM value represents the median value of the particle size for that particular PM (such as PM0.1, PM2.5, and PM10).
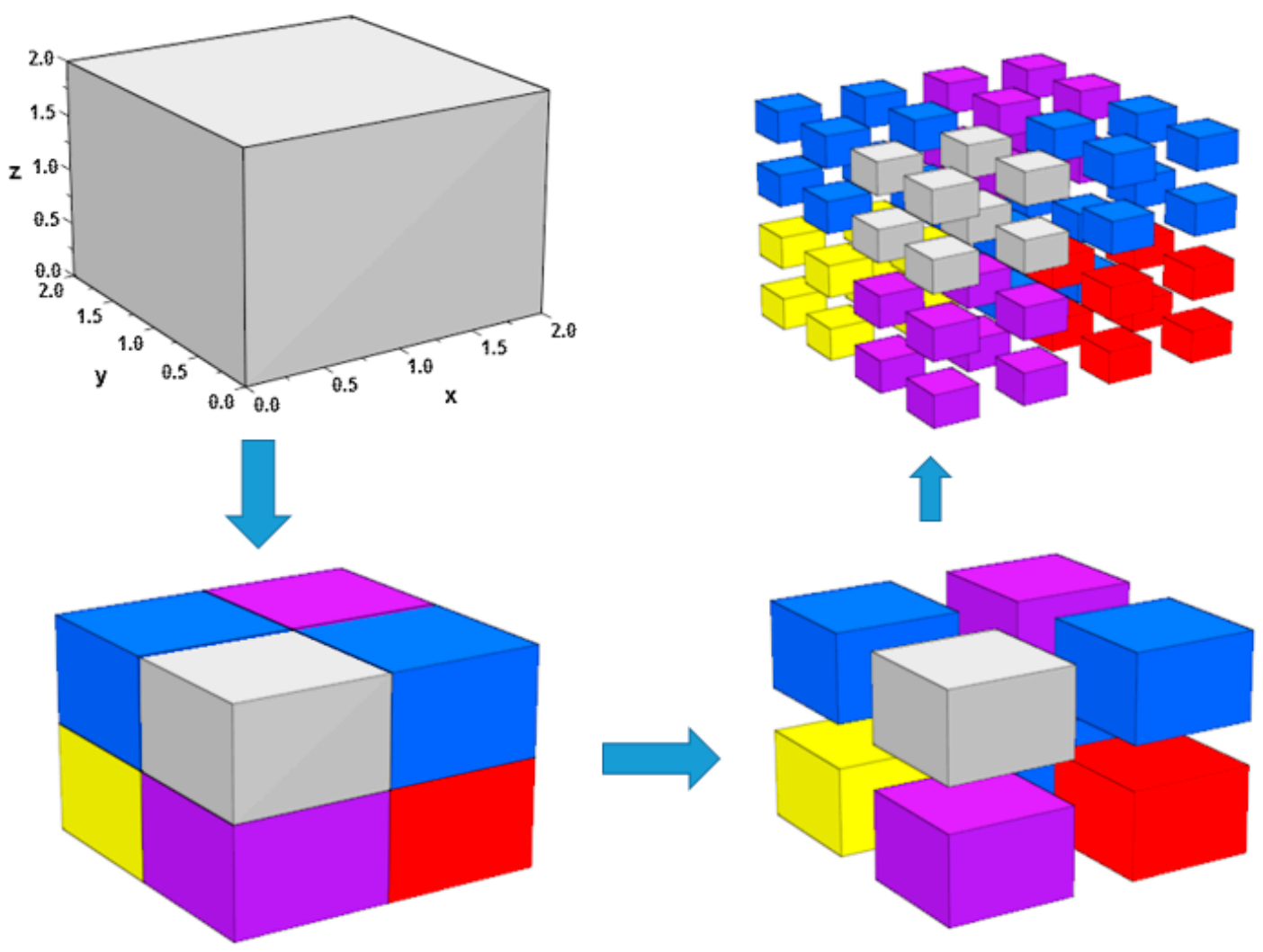
Figure 2. When the cube is divided into eight smaller parts, its surface area increases from $24 \mathrm{~m}^{2}$ to the total surface area of $48 \mathrm{~m}^{2}$. Further division into 64 parts will result in the total surface area of 96 $m^{2}$.

Table 1. The PM features and relation to the human health.

\begin{tabular}{|c|c|}
\hline PM feature & Influence on health \\
\hline Particle size & Smaller particles penetrate easier and deeper into organs \\
\hline Chemical composition & Lead $(\mathrm{Pb})$ or $\mathrm{PAH}$ cancirogenous particles are especially poisonous \\
\hline $\begin{array}{l}\text { Small particle collective } \\
\text { behavior }\end{array}$ & $\begin{array}{l}\text { The effect is not known, could be a cumulative effect, of the small and } \\
\text { larger particles }\end{array}$ \\
\hline Shape & $\begin{array}{l}\text { Higher or irregular shape is known to be a more damaging (i.e., } \\
\text { asbestos to the lungs) }\end{array}$ \\
\hline Charge & $\begin{array}{l}\text { Negatively charged nanoparticles may cross more easily the mucus } \\
\text { layer, comparing to the positively charged particles }\end{array}$ \\
\hline Biologics carrier & Proteins similar to allergens may cause immunoreactions \\
\hline
\end{tabular}

Acknowledgments: Rimantas Kodzius was supported by a guest scientist fellowship from the program "Promoting talents and scientific careers" at the German Federal Institute for Risk Assessment in Berlin, Germany. We appreciate the English proofreading of the article by Peter J. Choi, who is an instructor of Academic Preparatory Program at AUIS.

Author Contributions: R.K. conceptualized and wrote the review article. N.R. provided the calculations and the figure for the surface area. The article was critically read by X.G., D.K.S., M.Z., A.F.A., D.P., and S.D.

Conflicts of Interest: The authors declare no conflict of interest.

\section{References}

1. Cole, M.; Lindeque, P.; Fileman, E.; Halsband, C.; Goodhead, R.; Moger, J.; Galloway, T.S. Microplastic ingestion by zooplankton. Environ Sci Technol 2013, 47, 6646-6655.

2. Bateman, D.N. Carbon monoxide. Medicine 2003, 31, 41-42.

3. Weaver, L.K. Clinical practice. Carbon monoxide poisoning. The New England journal of medicine 2009, 360, 1217-1225.

4. Fan, H.C.; Wang, A.C.; Lo, C.P.; Chang, K.P.; Chen, S.J. Damage of cerebellar white matter due to carbon monoxide poisoning: A case report. Am J Emerg Med 2009, 27, 757 e $755-757$.

5. Gorman, D.; Drewry, A.; Huang, Y.L.; Sames, C. The clinical toxicology of carbon monoxide. Toxicology 2003, 187, 25-38.

6. Howland, M.A.; Lewin, N.; Nelson, L.; Goldfrank, L.; Hoffman, R. Carbon monoxide. Tenth Edition ed.; McGraw-Hill Education: 2014.

7. Davutoglu, V.; Zengin, S.; Sari, I.; Yildirim, C.; Al, B.; Yuce, M.; Ercan, S. Chronic carbon monoxide exposure is associated with the increases in carotid intima-media thickness and c-reactive protein level. The Tohoku journal of experimental medicine 2009, 219, 201-206.

8. Njuguna, J.; Pielichowski, K.; Zhu, H. Polymer nancomposites and other materials containing nanoparticles. Elsevier Science: 2014.

9. Carn, S.A.; Fioletov, V.E.; McLinden, C.A.; Li, C.; Krotkov, N.A. A decade of global volcanic so2 emissions measured from space. Sci Rep 2017, 7, 44095. 
533 10. Marsh, A.; Rovelli, G.; Song, Y.C.; Pereira, K.L.; Willoughby, R.E.; Bzdek, B.R.;

534

535

536

537

538

539

540

541

542

543

544

545

546

547

548

549

550

551

552

553

554

555

556

557

558

559

560

561

562

563

564

565

566

567

568

569

570

571

572

573 Hamilton, J.F.; Orr-Ewing, A.J.; Topping, D.O.; Reid, J.P. Accurate representations of the physicochemical properties of atmospheric aerosols: When are laboratory measurements of value? Faraday Discuss 2017, 200, 639-661.

11. Equipment, D.M. Suspended particulate matter definition. http://www.dust-monitoring-equipment.com/suspended-particulate-matter-definitio $\underline{\mathrm{n}-2 /}$

12. Koehler, K.A.; Peters, T.M. New methods for personal exposure monitoring for airborne particles. Curr Environ Health Rep 2015, 2, 399-411.

13. Schins, R.P.; Lightbody, J.H.; Borm, P.J.; Shi, T.; Donaldson, K.; Stone, V. Inflammatory effects of coarse and fine particulate matter in relation to chemical and biological constituents. Toxicology and applied pharmacology 2004, 195, 1-11.

14. Standardization, I.O.f. Iso 23210:2009 stationary source emissions. In Determination of PM10/PM2,5 mass concentration in flue gas -- Measurement at low concentrations by use of impactors, 2015; p 42.

15. Limited, D.E. Particulate pollution - pm10 and pm2.5. https://diamondenv.wordpress.com/2010/12/10/particulate-pollution-pm10-and-pm2 $\underline{-5 /}$

16. Hsu, Y.M.; Wang, X.; Chow, J.C.; Watson, J.G.; Percy, K.E. Collocated comparisons of continuous and filter-based pm2.5 measurements at fort mcmurray, alberta, canada. J Air Waste Manag Assoc 2016, 66, 329-339.

17. Akyuz, M.; Cabuk, H. Meteorological variations of pm2.5/pm10 concentrations and particle-associated polycyclic aromatic hydrocarbons in the atmospheric environment of zonguldak, turkey. J Hazard Mater 2009, 170, 13-21.

18. Deary, M.E.; Bainbridge, S.J.; Kerr, A.; McAllister, A.; Shrimpton, T. Practicalities of mapping pm10 and pm2.5 concentrations on city-wide scales using a portable particulate monitor. Air Qual Atmos Health 2016, 9, 923-930.

19. Ravikumar, D.; Sinha, P. The impact of photovoltaic (pv) installations on downwind particulate matter concentrations: Results from field observations at a 550-mwac utility-scale pv plant. J Air Waste Manag Assoc 2017, 67, 1126-1136.

20. Qin, X.; Bhave, P.V.; Prather, K.A. Comparison of two methods for obtaining quantitative mass concentrations from aerosol time-of-flight mass spectrometry measurements. Anal Chem 2006, 78, 6169-6178.

21. Cesaroni, G.; Forastiere, F.; Stafoggia, M.; Andersen, Z.J.; Badaloni, C.; Beelen, R.; Caracciolo, B.; de Faire, U.; Erbel, R.; Eriksen, K.T., et al. Long term exposure to ambient air pollution and incidence of acute coronary events: Prospective cohort study and meta-analysis in 11 european cohorts from the escape project. Bmj 2014, $348, \mathrm{f} 7412$.

22. Park, H.Y.; Gilbreath, S.; Barakatt, E. Respiratory outcomes of ultrafine particulate matter (ufpm) as a surrogate measure of near-roadway exposures among bicyclists. Environ Health 2017, 16, 6. 
574

575

576

577

578

579

580

581

582

583

584

585

586

587

588

589

590

591

592

593

594

595

596

597

598

599

600

601

602

603

604

605

606

607

608

609

610

611

612

613

614

615

616

23. Ham, S.; Lee, N.; Eom, I.; Lee, B.; Tsai, P.J.; Lee, K.; Yoon, C. Comparison of real time nanoparticle monitoring instruments in the workplaces. Saf Health Work 2016, 7, 381-388.

24. Tarik, M.; Foppiano, D.; Hess, A.; Ludwig, C. A practical guide on coupling a scanning mobility sizer and inductively coupled plasma mass spectrometer (smps-icpms). Journal of visualized experiments : JoVE 2017.

25. Starost, K.; Frijns, E.; Van Laer, J.; Faisal, N.; Egizabal, A.; Elizextea, C.; Blazquez, M.; Nelissen, I.; Njuguna, J. Assessment of nanoparticles release into the environment during drilling of carbon nanotubes/epoxy and carbon nanofibres/epoxy nanocomposites. J Hazard Mater 2017, 340, 57-66.

26. Kodzius, R.; Xiao, K.; Wu, J.; Yi, X.; Gong, X.; Foulds, I.G.; Wen, W. Inhibitory effect of common microfluidic materials on pcr outcome. Sensors and Actuators B: Chemical 2012, 161, 349-358.

27. Fuchs, N.A. The mechanics of aerosols. Pergamon Press: Oxford, 1964.

28. Fishler, R.; Sznitman, J. A novel aerodynamic sizing method for pharmaceutical aerosols using image-based analysis of settling velocities. Inhalation 2017, 11, 21-25.

29. Vu, T.V.; Ondracek, J.; Zdimal, V.; Schwarz, J.; Delgado-Saborit, J.M.; Harrison, R.M. Physical properties and lung deposition of particles emitted from five major indoor sources. Air Qual Atmos Health 2017, 10, 1-14.

30. Schulze, F.; Gao, X.; Virzonis, D.; Damiati, S.; Schneider, M.; Kodzius, R. Air quality effects on human health and approaches for its assessment through microfluidic chips. Genes 2017, 8, 244.

31. Harrison, R.M.; Giorio, C.; Beddows, D.C.; Dall'Osto, M. Size distribution of airborne particles controls outcome of epidemiological studies. The Science of the total environment 2010, 409, 289-293.

32. Holmes, H.A.; Pardyjak, E.R. Investigation of time-resolved atmospheric conditions and indoor/outdoor particulate matter concentrations in homes with gas and biomass cook stoves in nogales, sonora, mexico. J Air Waste Manag Assoc 2014, 64, 759-773.

33. Putaud, J.P.; Van Dingenen, R.; Alastuey, A.; Bauer, H.; Birmili, W.; Cyrys, J.; Flentje, H.; Fuzzi, S.; Gehrig, R.; Hansson, H.C., et al. A european aerosol phenomenology - 3: Physical and chemical characteristics of particulate matter from 60 rural, urban, and kerbside sites across europe. Atmospheric Environment 2010, 44, 1308-1320.

34. Yin, J.; Harrison, R.M. Pragmatic mass closure study for pm1.0, pm2.5 and pm10 at roadside, urban background and rural sites. Atmospheric Environment 2008, 42, 980-988.

35. Kovarik, W. Ethyl-leaded gasoline: How a classic occupational disease became an international public health disaster. Int J Occup Environ Health 2005, 11, 384-397.

36. Environment, U. Middle east west asia lead status map. https://www.unenvironment.org/resources/report/middle-east-west-asia-lead-status$\underline{\text { map }}$

37. Srogi, K. Monitoring of environmental exposure to polycyclic aromatic hydrocarbons: A review. Environ Chem Lett 2007, 5, 169-195. 
617 38. Roduner, E. Size matters: Why nanomaterials are different. Chemical Society reviews

618

619

620

621

622

623

624

625

626

627

628

629

630

631

632

633

634

635

636

637

638

639

640

641

642

643

644

645

646

647

648

649

650

651

652

653

654

655

656

657

658

2006, 35, 583-592.

39. Ghosh, C.K. Quantum effect on properties of nanomaterials. In Introduction to nano: Basics to nanoscience and nanotechnology, Sengupta, A.; Sarkar, C.K., Eds. Springer Berlin Heidelberg: Berlin, Heidelberg, 2015; pp 73-111.

40. Nelin, T.D.; Joseph, A.M.; Gorr, M.W.; Wold, L.E. Direct and indirect effects of particulate matter on the cardiovascular system. Toxicol Lett 2012, 208, 293-299.

41. Tomatis, M.; Turci, F.; Ceschino, R.; Riganti, C.; Gazzano, E.; Martra, G.; Ghigo, D.; Fubini, B. High aspect ratio materials: Role of surface chemistry vs. Length in the historical "long and short amosite asbestos fibers". Inhal Toxicol 2010, 22, 984-998.

42. Griessinger, J.; Dunnhaupt, S.; Cattoz, B.; Griffiths, P.; Oh, S.; Borros i Gomez, S.; Wilcox, M.; Pearson, J.; Gumbleton, M.; Abdulkarim, M., et al. Methods to determine the interactions of micro- and nanoparticles with mucus. European journal of pharmaceutics and biopharmaceutics : official journal of Arbeitsgemeinschaft fur Pharmazeutische Verfahrenstechnik e.V 2015, 96, 464-476.

43. Lai, S.K.; Wang, Y.Y.; Hanes, J. Mucus-penetrating nanoparticles for drug and gene delivery to mucosal tissues. Adv Drug Deliv Rev 2009, 61, 158-171.

44. Crameri, R.; Kodzius, R. The powerful combination of phage surface display of cdna libraries and high throughput screening. Comb Chem High Throughput Screen 2001, 4, 145-155.

45. Crameri, R.; Kodzius, R.; Konthur, Z.; Lehrach, H.; Blaser, K.; Walter, G. Tapping allergen repertoires by advanced cloning technologies. Int Arch Allergy Immunol 2001, 124, 43-47.

46. Andersson, A.; Rasool, O.; Schmidt, M.; Kodzius, R.; Fluckiger, S.; Zargari, A.; Crameri, R.; Scheynius, A. Cloning, expression and characterization of two new ige-binding proteins from the yeast malassezia sympodialis with sequence similarities to heat shock proteins and manganese superoxide dismutase. Eur J Biochem 2004, 271, 1885-1894.

47. Kodzius, R. High-throughput screening of enriched phage surface display libraries for rapid cloning of complex allergen repertoires. Paris Lodron University of Salzburg, Salzburg, 2002.

48. Kodzius, R.; Rhyner, C.; Konthur, Z.; Buczek, D.; Lehrach, H.; Walter, G.; Crameri, R. Rapid identification of allergen-encoding cdna clones by phage display and high-density arrays. Comb Chem High Throughput Screen 2003, 6, 147-154.

49. Kodzius, R.; Gojobori, T. Marine metagenomics as a source for bioprospecting. Mar Genomics 2015, 24 Pt 1, 21-30.

50. Bahadar, H.; Maqbool, F.; Niaz, K.; Abdollahi, M. Toxicity of nanoparticles and an overview of current experimental models. Iran Biomed J 2016, 20, 1-11.

51. Lee, J.; Park, E.Y.; Lee, J. Non-toxic nanoparticles from phytochemicals: Preparation and biomedical application. Bioprocess Biosyst Eng 2014, 37, 983-989.

52. Vallyathan, V.; Gwinn, M.R. Nanoparticles: Health effects-pros and cons. Environ Health Persp 2006, 114, 1818-1825. 
659 53. Buzea, C.; Pacheco, II; Robbie, K. Nanomaterials and nanoparticles: Sources and

660

661

662

663

664

665

666

667

668

669

670

671

672

673

674

675

676

677

678

679

680

681

682

683

684

685

686

687

688

689

690

691

692

693

694

695

696

697

698

699

700

701 toxicity. Biointerphases 2007, 2, MR17-71.

54. Megido, L.; Suarez-Pena, B.; Negral, L.; Castrillon, L.; Fernandez-Nava, Y. Suburban air quality: Human health hazard assessment of potentially toxic elements in pm10. Chemosphere 2017, 177, 284-291.

55. Jia, Y.Y.; Wang, Q.; Liu, T. Toxicity research of pm2.5 compositions in vitro. Int J Environ Res Public Health 2017, 14, 232.

56. Teng, C.; Wang, Z.; Yan, B. Fine particle-induced birth defects: Impacts of size, payload, and beyond. Birth Defects Res C Embryo Today 2016, 108, 196-206.

57. Bhatia, S.N.; Ingber, D.E. Microfluidic organs-on-chips. Nat Biotechnol 2014, 32, 760-772.

58. Kodzius, R.; Schulze, F.; Gao, X.; Schneider, M.R. Organ-on-chip technology: Current state and future developments. Genes (Basel) 2017, 8, 266.

59. Besis, A.; Tsolakidou, A.; Balla, D.; Samara, C.; Voutsa, D.; Pantazaki, A.; Choli-Papadopoulou, T.; Lialiaris, T.S. Toxic organic substances and marker compounds in size-segregated urban particulate matter - implications for involvement in the in vitro bioactivity of the extractable organic matter. Environ Pollut 2017, 230, 758-774.

60. Chiara Pietrogrande, M.; Barbaro, E.; Bove, M.C.; Clauser, G.; Colombi, C.; Corbella, L.; Cuccia, E.; Dalla Torre, S.; Decesari, S.; Fermo, P., et al. Results of an interlaboratory comparison of analytical methods for quantification of anhydrosugars and biosugars in atmospheric aerosol. Chemosphere 2017, 184, 269-277.

61. Harrison, R.M.; Beddows, D.C.S.; Hu, L.; Yin, J. Comparison of methods for evaluation of wood smoke and estimation of uk ambient concentrations. Atmospheric Chemistry and Physics 2012, 12, 8271-8283.

62. Sandradewi, J.; Prévôt, A.S.H.; Szidat, S.; Perron, N.; Alfarra, M.R.; Lanz, V.A.; Weingartner, E.; Baltensperger, U. Using aerosol light absorption measurements for the quantitative determination of wood burning and traffic emission contributions to particulate matter. Environ Sci Technol 2008, 42, 3316-3323.

63. Heal, M.R.; Naysmith, P.; Cook, G.T.; Xu, S.; Duran, T.R.; Harrison, R.M. Application of $14 \mathrm{c}$ analyses to source apportionment of carbonaceous pm2.5 in the uk. Atmospheric Environment 2011, 45, 2341-2348.

64. Pio, C.; Cerqueira, M.; Harrison, R.M.; Nunes, T.; Mirante, F.; Alves, C.; Oliveira, C.; Sanchez de la Campa, A.; Artíñano, B.; Matos, M. Oc/ec ratio observations in europe: Re-thinking the approach for apportionment between primary and secondary organic carbon. Atmospheric Environment 2011, 45, 6121-6132.

65. Harrison, R.M.; Yin, J. Chemical speciation of pm2.5 particles at urban background and rural sites in the uk atmosphere. J Environ Monit 2010, 12, 1404-1414.

66. Yin, J.; Harrison, R.M.; Chen, Q.; Rutter, A.; Schauer, J.J. Source apportionment of fine particles at urban background and rural sites in the uk atmosphere. Atmospheric Environment 2010, 44, 841-851.

67. Allan, J.D.; Williams, P.I.; Morgan, W.T.; Martin, C.L.; Flynn, M.J.; Lee, J.; Nemitz, E.; Phillips, G.J.; Gallagher, M.W.; Coe, H. Contributions from transport, solid fuel 
702

703

704

705

706

707

708

709

710

711

712

713

714

715

716

717

718

719

720

721

burning and cooking to primary organic aerosols in two uk cities. Atmospheric Chemistry and Physics 2010, 10, 647-668.

68. King, P.; Pham, L.K.; Waltz, S.; Sphar, D.; Yamamoto, R.T.; Conrad, D.; Taplitz, R.; Torriani, F.; Forsyth, R.A. Longitudinal metagenomic analysis of hospital air identifies clinically relevant microbes. PLoS One 2016, 11, e0160124.

69. Spector, J. Mapping global air pollution down to the neighborhood level. https://www.citylab.com/environment/2015/08/mapping-global-air-pollution-downto-the-neighborhood-level/400337/

70. Hsu, A.; Zomer, A. An interactive air-pollution map. https://www.theatlantic.com/health/archive/2014/06/the-air-we-breathe/372411/

71. Stedman, J.R.; Kent, A.J.; Grice, S.; Bush, T.J.; Derwent, R.G. A consistent method for modelling pm 10 and pm 2.5 concentrations across the united kingdom in 2004 for air quality assessment. Atmospheric Environment 2007, 41, 161-172.

72. Carruthers, D.J.; Edmunds, H.A.; McHugh, C.A.; Singles, R.J. Development of adms-urban and comparison with data for urban areas in the uk. In Air pollution modeling and its application xii, Gryning, S.-E.; Chaumerliac, N., Eds. Springer US: Boston, MA, 1998; pp 467-475.

73. Dedele, A.; Miskinyte, A. The statistical evaluation and comparison of adms-urban model for the prediction of nitrogen dioxide with air quality monitoring network. Environ Monit Assess 2015, 187, 578. 